\title{
FILITERATURA: BASE DE DATOS RELACIONAL EN HEURIST DE LITERATURA EN ESPAÑOL EN FILIPINAS Y SOBRE FILIPINAS
}

\author{
FILITERATURA: A HEURIST RELATIONAL DATABASE \\ OF LITERATURE IN SPANISH ABOUT THE PHILIPPINES \\ OR PUBLISHED IN THE PHILIPPINES
}

\section{Rocío ORTUÑO CASANOVA}

Universidad de Amberes

rocio.ortuno@uantwerpen.be

\begin{abstract}
Resumen: Filipinas ha sido siempre un tema marginal en los estudios hispánicos. Sin embargo, la producción en español desde y sobre la excolonia fue abundante y tuvo cierta trascendencia política y cultural durante la Edad de Plata. Para dar visibilidad a esta literatura y asentar las bases de una historia de la literatura filipina y sobre Filipinas en español, se ha creado Filiteratura. Filiteratura es una base de datos relacional construida en Heurist que reúne literatura comprendida en lo que hoy se conoce como filipiniana: obras en español publicadas en Filipinas (por filipinos o no) y obras en español publicadas sobre Filipinas en cualquier otro lugar del mundo entre 1850 y 1973. La base de datos conecta con diversas bibliotecas y repositorios físicos y online para facilitar el acceso y el estudio cuantitativo de estas obras. Asimismo, incluye información relacionada con los autores y sus obras como periódicos, imprentas y premios literarios, que permiten una reconstrucción del campo literario en torno a Filipinas y la conexión con otros proyectos sobre bibliografía, prensa periódica y traducción en el mundo hispánico.
\end{abstract}


Palabras clave: Literatura hispanofilipina. Campo literario. Campo cultural. Base de datos relacional. Biblioteca digital.

\begin{abstract}
The Philippines has always been a marginal topic in Hispanic Studies. However, between 1868 and 1936, there was a relevant amount of literary production in Spanish about and from the ex colony. It had some political and cultural importance as well. Filiteratura has been created in order to make this literature visible and to set the grounds for a History of Literature in Spanish from and about the Philippines. It is a relational database built on Heurist that gathers filipiniana literature, that is, works in Spanish published in the Philippines (by Filipinos or by other nationals), and works in Spanish about the Philippines published in any other place in the world, between 1850 and 1973. The relational database connects with several libraries and online repositories to facilitate the access and study of these works. It also includes information related to other components of the literary field such as newspapers, publishers and literary awards to which authors and works are connected. This allows a reconstruction of the literary field around the Philippine and linkages with other projects about bibliography, periodical press and translation in the hispanic world.
\end{abstract}

Key Words: Fil-Hispanic literature. Literary field. Cultural field. Relational database. Digital library

\title{
1. PRESENTACIÓN
}

En 1905, Wenceslao Retana definía así los libros que para él comprendían el conjunto de la bibliografía filipina y que se disponía a compilar en los cinco volúmenes de su Aparato bibliográfico de la historia general de Filipinas:

a) Los impresos en Filipinas, sin distinción de materia: porque todos ellos son indispensables para el cabal estudio de la tipografia del Archipiélago. b) Los que tratan de Filipinas, sea la que sea la lengua en que estén escri- 
tos y el lugar donde hayan sido estampados: porque son más ó menos necesarios para el estudio de dicho país.

c) Y los publicados por filipinos, versen de lo que versen y sin reparar en el pie de imprenta: porque nos sirven de mucho para darnos la medida de la potencia intelectual de los allí nacidos, su laboriosidad, sus gustos, inclinaciones, etcétera (Retana, 1906: ii).

Esta caracterización fue la base para la creación del concepto posterior de filipiniana, en el que se basan hoy en día las bibliotecas filipinas para definir todo aquello publicado relacionado con Filipinas, como se indica en la página web de la Biblioteca Nacional de Filipinas, que traduce literalmente al inglés el texto de Retana ${ }^{1}$. El concepto tiene sentido en un país poscolonial de geografía discontinua conformado por una amalgama de lenguas y culturas que lleva desde finales del siglo XIX a la búsqueda de una identidad nacional. Dicha identidad nacional se alimenta en parte de la filipiniana: lo que los filipinos y los extranjeros han dicho sobre el país.

Apartir también de esa definición, se han acotado algunos parámetros para crear la base de datos Filiteratura ${ }^{2}$. Filiteratura es una base de datos relacional alojada en Heurist y constituye uno de los principales resultados del proyecto de investigación "Filippijnen op het kruispunt: studie van de internationale aanwezigheid in het Filippijnse literaire veld in het Spaans tussen 1872 en 1945" (Filipinas en la encrucijada: estudio de las influencias internacionales en el campo literario filipino en español entre 1872 y 1945) subvencionado por el gobierno de Flandes, Bélgica, mediante el Fondo para la Investigación Universitaria (BOF: Bijzondere onderzoeksfondsen) de la Universidad de Amberes. Esta base de datos extrae información de los catálogos de varias bibliotecas del mundo y que contiene información sobre obras literarias en español, o bien publicadas en Filipinas, o bien que tratan sobre este país y que fueron publicadas entre 1850 y $1973^{3}$. Como se ve, en este caso hemos limitado, respecto a la definición de Retana, las obras incluidas a obras literarias relacionadas con la filipiniana, además de la literatura de autores extranjeros en español sobre cualquier

\footnotetext{
${ }^{1}$ Véase $h t t p: / / w e b . n l p . g o v . p h / n l p / ? q=$ node/656 [05/12/2019].

${ }^{2}$ Véase https://filiteratura.uantwerpen.be/ [12/12/2019].

${ }^{3}$ También contiene obras originalmente escritas en español, pero traducidas a otros idiomas como es el caso del Noli me tangere.
} 
tema publicados en Filipinas, lo que nos permitirá saber qué se leía en el archipiélago y de dónde vienen sus influencias. Asimismo, aparte de los géneros tradicionales, se han incluido algunos géneros híbridos ${ }^{4}$, como los libros de viaje, los diarios, cuadros o escenas costumbristas propias del periodismo literario y textos ensayísticos que ahondan en la sociología del archipiélago.

Inicialmente el límite cronológico se situaba entre 1872, fecha del motín de Cavite, uno de los primeros intentos de boicot al gobierno español con una consciente intencionalidad nacionalista panfilipina y 1973, año en que el español se eliminó por primera vez de la Constitución filipina. El límite cronológico se amplió hasta 1850 en una segunda fase para entroncar con el trabajo bibliográfico realizado por la historiadora Ruth de Llobet, que ha compilado obras sobre Filipinas de cualquier lengua y país hasta 1850 y está en proceso de sistematización y digitalización. Estos márgenes contienen y exceden el periodo de la denominada Edad de Plata, que iría de 1868 (año de la Revolución Gloriosa) a 1936 con el comienzo de la Guerra Civil española (Urrutia Cárdenas, 1999: 583). De hecho, el pico de producción más alto coincide con este periodo: de un total de 755 ediciones, el repositorio contiene 540 obras editadas en estos años, de las cuales, 119 son obras sobre Filipinas publicadas en España, 399 son obras en español publicadas en Filipinas y el resto, obras sobre Filipinas publicadas en otros lugares.

En las últimas tres décadas del siglo XIX, la reflexión posindependencia de las colonias americanas sobre qué hacer con el resto de las colonias había llevado a una abundante literatura desde España sobre Filipinas, especialmente en torno a la Exposición de Filipinas que se celebró en el Palacio de Cristal del Parque del Retiro de Madrid en 1887: desde Benito Pérez Galdós (Valmaseda: 2014) a Emilia Pardo Bazán (Bardavío-Estevan, 2018), pasando por Felipe Trigo (Martínez San Martín and Garrido

\footnotetext{
${ }^{4}$ Consideramos aquí géneros híbridos basándonos en la definición de Mikhail Bakhtín para decir que son textos que incluyen "a deliberate coding of multiplicity within the syntax of a single phrase or sentence, producing parody, polysemy, or some other disjuncture between meaning and intent" (Kapchan y Strong, 1999: 243). En el caso de los textos híbridos que aquí se incluyen, tienen en parte una intención literaria e incluyen recursos para el disfrute del lector, mientras que no acaban de ser textos de ficción o totalmente de placer al albergar información e intenciones relacionadas con la difusión del conocimiento, y que pretenden a menudo conseguir beneficios económicos para los países (España y Filipinas) y para los lectores en la línea de lo que sugiere Mary Louise Pratt que ocurre en los textos anglosajones en su libro Imperial Eyes (2017: 201).
} 
Gallardo, 1983: 34-42) y los muchos escritores, periodistas y aficionados de la escritura que pasaron periodos del servicio militar o la propia Guerra de Independencia en Filipinas, las menciones al archipiélago asiático inundan el mercado editorial y la prensa española.

Mientras, en Filipinas, se publican sobre todo traducciones al castellano de obras de la literatura universal y las ocurrencias literarias de españoles viviendo en el país, normalmente vinculados con el periodismo de las islas. La situación cambia a partir de 1902. Con la invasión estadounidense comienza la Edad de oro de la literatura filipina en español, que concluirá en torno a 1935. A partir de 1936, según Florentino Rodao, la Guerra Civil dividió las perspectivas y cambió la imagen de España, debilitando la identificación que quedara con la península (Rodao, 1996: 169). En la II Guerra Mundial, conforme España acercaba posiciones con el eje, las élites filipinas tomaron distancia debido al peligro (y luego al hecho) de la invasión japonesa. En la Batalla de Manila que marcó el final de la Guerra en el archipiélago, Intramuros y Ermita, bastiones del español en la capital, fueron totalmente destruidas, con la pérdida de vidas y el exilio masivo a España que aquello supuso (Rodao, 1996: 171).

La literatura filipina en español no volvería a levantar cabeza airosa - aunque sigue produciendo alguna obra nostálgica de vez en cuandopero el tema filipino tuvo todavía cierta importancia durante el franquismo. El régimen, que soñaba con el Imperio, vio cómo desde la guerra las que habían sido colonias insignia, encabezadas por México, le daban la espalda y acogían a los refugiados republicanos. Se volcó entonces con los territorios que aún le quedaban: Guinea Ecuatorial, el Protectorado y Filipinas, que, a pesar de no ser ya colonia, se había posicionado de forma mayoritaria a favor de los sublevados y que mantenía una imagen romántica de España como madre de una comunidad hispanófona a cuya ascendencia se debía. Esto provocó que varias personalidades preminentes de la cultura del régimen como fueron Ernesto Giménez Caballero, Agustín de Foxá, Blas Piñar y Conrado Blanco, viajaran a Filipinas y escribieran sobre sus viajes y su experiencia. También continuó un goteo de relatos de la Guerra de Independencia de Filipinas y de diferentes experiencias de viajeros que, sobre todo a partir del estreno de Los últimos de Filipinas en 1946 y de la repatriación de los supervivientes de la II Guerra Mundial en 1947, cobraron cierta presencia en la triste y limitada escena literaria española del momento. Finalmente, en los años 50 hubo otro repunte gracias 
a la popular literatura de kiosco de tema bélico liderada por la editorial Toray y su colección "Hazañas bélicas" que ambienta muchas de sus historias en la II Guerra Mundial en Filipinas.

La literatura filipina en español es un tema olvidado y toda una rareza en los estudios hispánicos (Mojarro, 2019: 1). Mientras en Filipinas no se estudia más que la obra traducida de José Rizal en las escuelas, obligados por la variedad lingüística del país a ofrecer un muestrario muy reducido de la literatura de cada lengua en las clases (Donoso and Gallo, 2011: 12), la situación en el resto de universidades en que se enseñan estudios hispánicos no es mucho más halagüeña (Ortuño Casanova, 2017: 60-61). Parte de la razón es la poca accesibilidad que tradicionalmente han tenido las obras relevantes de su literatura (De la Peña, 2011). La desconexión del archipiélago del mundo hispánico fue imparable a partir de la independencia de México. A pesar de que a lo largo de la primera mitad del siglo XX hubo algunos contactos con España y América Latina -me refiero a las visitas culturales realizadas por literatos españoles a Filipinas como Gerardo Diego o las de filipinos que van a Latinoamérica como Jesús Balmori y Alejandro Paterno-, y que los contactos informales se continuaron, los esfuerzos norteamericanos por deshispanizar el archipiélago surtieron efecto y redujeron la producción literaria (y los lectores) en español a algo completamente marginal.

La II Guerra Mundial supuso un duro revés para la preservación del patrimonio bibliográfico filipino. En la Batalla de Manila, la mayor parte del fondo de la Biblioteca Nacional fue destruido, salvándose solo 36.600 volúmenes de los 733.000 existentes antes de la guerra. La Universidad de Filipinas quedó con solo 3.000 volúmenes de los 147.000 existentes antes de 1941 (Hernández, 2001: 337). A esta destrucción repentina de volúmenes debe sumarse la destrucción paulatina que las inclemencias meteorológicas y desastres derivados han ido infligiendo a los fondos y diversas iniciativas: en 2016 un incendio acabó con la Facultad de Humanidades de la Universidad de Filipinas, destruyendo consigo la biblioteca Pablo K. Botor del Departamento de lenguas ${ }^{5}$. En mayo de 2019 otro incendio afectó al edificio principal del archivo histórico de Filipinas y diez años antes, en 2009, el tifón Ondoy (nombre internacional Ketsana),

${ }^{5}$ Véase $h t t p: / / c n n p h i l i p p i n e s . c o m / m e t r o / 2016 / 04 / 01 / u p$-diliman-faculty-center-fire.html [26/01/2019]. 
inundó los servidores del proyecto impulsado por Vibal Foundation y dirigido por Carlos Madrid, filipiniana.org, destruyendo para siempre un trabajo pionero en digitalización de materiales filipinos y sobre Filipinas.

En este contexto, las iniciativas de digitalización se vuelven especialmente necesarias a la hora de preservar un patrimonio en riesgo constante. Estas se vienen sucediendo a lo largo de la segunda década del siglo $\mathrm{XXI}^{6}$. En 2014 se inauguraba el portal sobre literatura filipina en español de la Biblioteca Virtual Miguel de Cervantes que reunía en un mismo espacio y de manera contextualizada obras escaneadas en Filipinas de difícil acceso desde fuera de la isla de Luzón (Ortuño Casanova, 2014). Los objetivos eran tres: facilitar la labor a los investigadores, aumentar la visibilidad de esta literatura y ofrecer un contexto para las obras digitalizadas. Sin embargo, teniendo en cuenta los rápidos avances en materia de digitalización, la colección de PDFs realizados con pocos recursos y calidad variable, pronto se vio superada por otras copias digitales que se fueron poniendo online de esos y otros libros por parte de diversas bibliotecas. Por poner algunos ejemplos: la Universidad de Michigan va compilando desde 2007 en el portal The United States and Its Territories multitud de obras relacionadas con Filipinas escritas entre 1870 y 1925 gracias a un proyecto subvencionado por el National Endowment for the Humanities $^{7}$. La colección es amplia, incluye obras no literarias, y está disponible en diversos formatos (pdf, jpg, txt...).

$\mathrm{Al}$ otro lado del Atlántico, el agregador Europeana contiene 541 objetos bajo la descripción de texto completo, en castellano, con Filipinas como término de búsqueda ${ }^{8}$, y la biblioteca digital de la Universidad de Santo Tomás de Manila, Filipinas, contiene 1190 libros digitalizados en la colección Filipiniana (sin contar las revistas y periódicos publicados en Filipinas) ${ }^{9}$. El problema de estas y otras iniciativas para el campo de los estudios hispánicos es que, con la excepción de la Biblioteca Virtual Miguel de Cervantes, ninguna está centrada exclusivamente en la literatura filipina, con lo cual, la dispersión, a pesar de la ventaja de que estén

\footnotetext{
${ }^{6}$ Una panorámica de estas iniciativas puede verse en Ortuño Casanova y Sarmiento (2020).

${ }^{7}$ Véase https://quod.lib.umich.edu/p/philamer [09/12/2019].

${ }^{8}$ Véase https://www.europeana.eu/portal/es/search?f\%5BTEXT_FULLTEXT\%5D\%5B\%5D= true \&f $\% 5 B T Y P E \% 5 D \% 5 B \% 5 D=T E X T \& q=$ filipinas \&f $\% 5 B L A N G U A G E \% 5 D \% 5 B \% 5 D=e s$ [09/12/2019].

${ }^{9}$ Véase http://digitallibrary.ust.edu.ph/cdm/search/collection/section5 [09/12/2019].
} 
accesibles en formato digital, sigue siendo un hecho: de momento no hay un catálogo completo de lugares en los que se puede acceder a libros filipinos o sobre Filipinas (digital o presencialmente). Los archivos filipinos que contienen libros digitales - entre ellos la mencionada biblioteca digital de la Universidad de Santo Tomás y la Filipinas Heritage Library de la Biblioteca Museo Ayala - son por lo general poco conocidos fuera del país ${ }^{10}$.

Por otro lado, existe también un problema de las antologías: el canon de la literatura filipina en español se ha ido estableciendo por medio de diferentes obras que han adoptado criterios más políticos que literarios. Esto se debe en parte a que la Edad de Oro de la literatura filipina en español surge como reacción a la imposición del inglés por la colonización norteamericana, con lo que tiene cierto cariz combativo de defensa de unos valores y una perspectiva de la nación filipina. Asimismo, los principales escritores filipinos en español que se han antologado en Filipinas han sido políticos o héroes nacionales (Ortuño Casanova, 2017), con lo que la historia de esta literatura queda coja y sesgada. La última historia de la literatura filipina en español más o menos completa que se ha publicado consta de apenas 90 páginas y fue publicada en la Editora Nacional por Luis Mariñas, embajador español en Filipinas durante los últimos años del Franquismo (Mariñas Otero, 1974). La obrita está pues irremediablemente marcada por las aspiraciones imperialistas del régimen.

\section{OBJETIVOS}

Una vez finalizado el portal de literatura filipina en español de la Biblioteca Virtual Miguel de Cervantes (BVMC), y dada la situación descrita anteriormente, se identificaron otra serie de necesidades que cubrir y que pasaron a ser objetivos de otros dos proyectos con vocación de unirse: Filiteratura y Philperiodicals ${ }^{11}$.

\footnotetext{
${ }^{10}$ Véase https://www.filipinaslibrary.org.ph/ [09/12/2019].

${ }^{11}$ Philperiodicals es un proyecto TEAM subvencionado por la agencia belga de cooperación académica VLIRUOS y liderado por las universidades de Amberes y de Filipinas con el que se está creando un repositorio digital de prensa histórica filipina cuya conexión futura con Filiteratura servirá para completar este mapa del campo literario filipino añadiendo textos publicados en prensa y contribuciones de los autores a los diferentes periódicos. Véase hosting.uantwerpen.be/
} 
La primera necesidad es la de recabar datos para sustentar una historia de la literatura filipina en español actualizada que permita a su vez la reconstrucción de las relaciones literarias entre los países hispanohablantes y Filipinas y de la literatura filipina en español. Esto, en el caso de la base de datos Filiteratura, se ha concretado en cuatro objetivos:

1. Centralizar las obras literarias en español publicadas en o sobre Filipinas entre 1872 (luego 1850) y 1973 digitalizadas en plataformas genéricas que las albergan dentro de su colección general y en la BVMC. De este modo los investigadores no tienen que ir buscándolas en los diferentes repositorios — que podrían además desconocer-. Desde Filiteratura se proporcionan enlaces a las obras en los repositorios.

2. Localizar otras obras existentes del mismo periodo que, sin estar digitalizadas, están disponibles en archivos y bibliotecas, e indicar dónde están.

3. Poner de manifiesto las relaciones entre los autores filipinos en español y los de otros países y la circulación de ideas y estéticas en el mundo hispánico.

4. Contribuir al retrato sociológico del campo literario y cultural filipino e hispánico, proporcionando las herramientas para hallar conexiones entre premios, periódicos, autores, editoriales, gobiernos y oficios.

\section{METODOLOGÍA}

\subsection{La búsqueda y la ubicación de las obras}

Dados los objetivos de centralización de materiales y de facilitar la búsqueda documental a los investigadores, se ha dado prioridad a las versiones online de los documentos. Es decir, si hay una versión online, no se ofrece su localización en otras bibliotecas. Los lugares donde se han buscado las obras online han sido:

- El portal de literatura filipina en español de la Biblioteca Virtual Miguel de Cervantes.

philperiodicals/ [14/10/2018]. 
- La Biblioteca Digital Hispánica de la Biblioteca Nacional de España.

- La colección de la biblioteca de la Universidad de Michigan llamada "The United States and its Territories. 1870-1925: The Age of Imperialism".

- Las colecciones de otras universidades estadounidenses albergadas en Hathi Trust (siempre que el acceso al texto completo esté disponible en todo el mundo).

- Archive.org.

- La Biblioteca Digital de la AECID.

- La Filipinas Heritage Library de Ayala Museum.

- La Biblioteca digital de la Universidad de Santo Tomás de Manila.

- Googlebooks, que tiene de acceso libre la colección completa de las obras de Antonio Pérez de Olaguer.

Las obras encontradas en estas colecciones están marcadas como online. En la actualidad contiene 254 ediciones de obras online. Si hay más de un lugar que contiene una misma edición online, se ofrecen todos los enlaces existentes.

En el caso de las obras que no están disponibles online, aparecen como Localización: Library. De este tipo, la base de datos contiene 517. El sistema ha consistido en buscar primero aquellas obras presentes en www.worldcat.org. Si estaban en Worldcat, se ha ofrecido el enlace permanente a la edición en Worldcat, en lugar de a todos los catálogos en los que estaba presente la obra. A continuación, se ha buscado en 8 catálogos que no están incluidas en Worldcat:

- Biblioteca del Seminario de los Agustinos de Valladolid.

- Biblioteca de la Universidad de Santo Tomás de Manila.

- Biblioteca de la Universidad de Filipinas en Diliman.

- Filipinas Heritage Library del museo y biblioteca Ayala y Librarylink $^{12}$.

${ }^{12}$ Este consorcio de bibliotecas que volcaban en un mismo catálogo sus obras de Filipiniana parece que dejó de funcionar en 2015 (Susmita, 2013: 176). Véase: http:// 
- Rizal Library de la Universidad Ateneo de Manila.

- Biblioteca Sancho el Sabio de la Fundación Vital de Vitoria (donde se encontró un único ejemplar de la edición original de Amoríos de Juana y Manuel de José Manuel Echeita editada en Manila).

Las obras se han buscado en las bibliotecas filipinas incluso si estaban presentes en Worldcat (pero no online) para facilitar el trabajo también de los investigadores radicados en Filipinas.

La metodología de búsqueda de estas obras ha ido cambiando debido a las diferentes características de las bibliotecas. Para las obras editadas en Filipinas, se ha comenzado con tres conjuntos de obras: las presentes en el portal de literatura filipina en español de la BVMC, las obras en español que estaban en el volumen sobre literatura del catálogo de la enciclopedia de Artes del Cultural Center of the Philippines así como los autores presentes en este volumen (Tiongson, 1994) y los autores y obras presentes en La literatura filipina en castellano de Luis Mariñas (Mariñas Otero, 1974). Desgraciadamente, las obras de muchos de los autores presentes en este libro no se han encontrado en ninguno de los catálogos consultados, aunque de muchos sí que las hay en periódicos.

A partir de ahí, se ha realizado (1) búsqueda de nombres de autores para encontrar obras suyas ausentes en los libros y el portal mencionados y (2) una búsqueda de todos los libros publicados por las imprentas que habían publicado los de la primera búsqueda. Un problema ha sido que en muchos repositorios no se puede buscar por editoriales/imprentas. Sí que se puede en el catálogo de la biblioteca de la Universidad de Filipinas, que permite buscar por el campo publisher. La Biblioteca Nacional de España permite también una búsqueda de los datos de publicación en su opción de Búsqueda avanzada del catálogo. En el resto, puede hacerse con una búsqueda por palabra clave (keyword) entrecomillada (imprenta Fajardo, por ejemplo). Esta búsqueda comenzó ya a dar como resultados algunas obras extranjeras publicadas en Filipinas. Llaman especialmente la atención las obras de escritores franceses traducidas al español y publicadas en Manila a finales del siglo XIX (55), entre las cuales ninguna es de poesía. Digo que llama la atención porque precisamente se ha criticado a los poetas

opac.librarylink.org.ph/ [18/12/2019]. 
filipinos la imitación acrítica de los autores simbolistas y parnasianistas franceses (Retana, 1909: 19), cuando las obras de ninguno de ellos han sido publicadas en español en Filipinas. Esto nos hace pensar que ha habido formas alternativas para su llegada y difusión al archipiélago filipino que deberán estudiarse, entre otras, la publicación en prensa.

Entre estos resultados encontramos también 302 ediciones de obras de españoles y españolas y 528 de filipinos y filipinas. Dada la situación colonial, el término españoles en este caso aglutina a las personas nacidas en la Península Ibérica excluyendo Portugal, en las Islas Baleares o en las Islas Canarias; por su parte, son filipinos/as, aquellos nacidos en el archipiélago filipino. En resultado de las ediciones filipinas es algo tramposo: de esas 528 ediciones, las del Noli me tangere y El filibusterismo suman 94 en diferentes idiomas.

La búsqueda de obras de autores/as nacidos en otros países (pongamos por caso Avelina Correa que es cubana) ha sido algo más difícil por no existir una bibliografía sistemática sobre las menciones a las mismas ${ }^{13}$. Además, ha resultado complicado decir cuándo una obra trata sobre Filipinas. ¿Es una obra sobre Filipinas si Filipinas es mencionada una vez? En este caso hemos intentado incluir solo obras que traten significativamente de Filipinas, en las que la mayor parte de la acción se desarrolle en el país asiático, o bien que alguien de dicho país o la situación juegue un papel importante en la trama de la historia o en el poema. Así pues no encajan las obras de Benito Pérez Galdós en las que se menciona Filipinas someramente, por ejemplo (Valmaseda, 2014), pero sí aquellas en las que hay un personaje filipino prominente (o incluso un objeto) como es el caso de la obra teatral Mi tía de Filipinas (Torrado, 1948), aunque la acción se desarrolle en España.

La solución encontrada ha sido en primer lugar buscar lo publicado en imprentas filipinas y en segundo lugar realizar búsquedas temáticas. Éstas siempre son difíciles de sistematizar dado que las diferentes bibliotecas tienden a usar diferentes nomenclaturas para sus clasificaciones temáticas (subjects) y no suele existir consistencia incluso dentro de las bibliotecas. Por ejemplo, en la Biblioteca de los agustinos de Valladolid aparecen bajo

\footnotetext{
${ }^{13}$ La obra de Ortiz Armengol Letras en Filipinas (1999) contiene algunas obras españolas sobre Filipinas, así como la de García Castellón Estampas y cuentos de la Filipinas hispánica (2001). Se han consultado ambos libros, pero en ninguno de ellos la recopilación es sistemática y además la selección es muy limitada.
} 
las palabras clave literatura filipina española 230 resultados que incluyen mezcladas obras escritas por hispanohablantes no filipinos como Vicente Barrantes y filipinos como Lourdes Brillantes, y traducciones al español de autores no hispanohablantes, realizadas en Filipinas, como la novela Ascanio de Alejandro Dumas, traducida para ser publicada en Diario de Manila en 1850. Para completar la búsqueda se han introducido palabras relacionadas con la geografía filipina en la búsqueda de los títulos, temas y palabras clave: Filipin**, Luzón, Visayas, Cebú, Iloilo, Mindanao, Sangley**, Manila, Taal (volcán) y Panay junto con los criterios temporales y de que estuviera escrita en castellano. Además, en las bibliotecas filipinas se ha buscado simplemente obras en español dentro de la sección Filipiniana, discriminando una por una las que son literarias según nuestra definición y las que no.

Hemos decidido excluir de la búsqueda las antologías, al menos de momento. La razón para ello es que no siempre están accesibles y por tanto no podíamos saber qué obras habían incluido, con lo que, aunque hubiera sido muy útil para ver la repercusión y difusión de las obras y afinar así la descripción del campo literario, han quedado pospuestas para una segunda fase. Sí que existe, sin embargo, un criterio para medir la repercusión y difusión de las obras en Filiteratura, que es atender al número de ediciones y las traducciones. Se han incluido aquellas obras que fueron publicadas por filipinos o sobre filipinas originalmente en español y que han tenido traducciones a otras lenguas. Así se puede ver, por ejemplo, la gran difusión de la novela Noli me tangere con traducciones al polaco, al japonés, al chino, al húngaro y a otras 10 lenguas.

No obstante, se encuentran ciertas dificultades. En la actualidad, los catálogos de las bibliotecas sirven para mucho más que para buscar un libro del que ya se conocen los datos principales. En este sentido, algunas iniciativas relacionadas con las Humanidades Digitales están impulsando el diálogo entre investigadores y bibliotecarios para que las búsquedas se faciliten. Es el caso del grupo de DARIAH sobre datos bibliográficos ${ }^{14}$ y el foro sobre digitalización, iniciativas digitales y buenas prácticas celebrado en la Universidad de Filipinas (Diliman Campus) en noviembre de 2019. A pesar de los pasos emprendidos, todavía queda trabajo que hacer y esto

\footnotetext{
${ }^{14}$ Véase https://www.dariah.eu/activities/working-groups/bibliographical-data-bibliodatal [15/12/2019].
} 
ha repercutido en las posibilidades de semiautomatización de la búsqueda.

En primer lugar, algunos de los catálogos utilizados estaban en plena transición. Así pues, la biblioteca del seminario de los agustinos de Valladolid, cuyos fondos aun no están enteros online, estaba pasando a Koha, con lo que hubo periodos en los que el catálogo era inaccesible y los enlaces permanentes al mismo cambiaron. Por su parte, la National Library of the Philippines lleva dos años de reformas estructurales. Durante la duración de estas reformas, solo permiten el acceso desde su catálogo online a las tesis y tesinas. Durante un tiempo se pudo hacer búsquedas en el catálogo desde Google buscando nlp koha más el título o el autor deseado, o incluso nlp koha filipiniana. Sin embargo, esto ya no es posible y los enlaces permanentes que ofrecían ya no funcionan. Por esta razón hemos tenido que cambiar el URL por el nombre de la biblioteca. El catálogo de la Biblioteca de la Universidad de Filipinas, aunque ha estado también desaparecido durante algunos meses para su acceso desde fuera de Filipinas debido a algunos ciberataques, está ya plenamente disponible.

La cuestión del URL permanente ha sido también problemática en las búsquedas en la biblioteca de UST y en la del catálogo de la University of the Philippines. En el catálogo de los fondos no digitales de la Benavides Library ${ }^{15}$, no existen los enlaces permanentes y hay que enlazar la búsqueda realizada. Lo mismo ocurre con el catálogo de la biblioteca principal de la University of the Philippines ${ }^{16}$, con el inconveniente añadido de que la sesión en este catálogo caduca y los enlaces dejan de funcionar.

En el caso del catálogo de la Biblioteca Nacional de España presenta algunos problemas para guardar los metadatos de manera automatizada por dos razones: la primera es que no identifica editorial e imprenta, términos que a menudo en el siglo XIX y principios del XX iban de la mano. Por lo tanto, en la mayor parte de los registros del catálogo de antes de 1973, el campo Datos de publicación aparece algo así: “[s.1.]: [s.n.], 1893 (Manila: Imp. de la Revista Mercantil)" (Lozano de Vilchez, 1893). Las herramientas de compilación bibliográfica como Zotero, que es la que hemos usado, identifican solo la primera parte, con lo que asumen que el lugar y la editorial son desconocidas y hay que entrar en el propio registro para introducir a mano la información que aparece a continuación entre

${ }^{15}$ Véase https://ustlib.ust.edu.ph/ [15/12/2019].

${ }^{16}$ Véase https://www.mainlib.upd.edu.ph/[18/12/2019]. 
paréntesis. De esta forma, además, se dificulta la búsqueda por editoriales. Finalmente, una vez superados todos estos problemas, surge el de identificar idiomas de traducción, especialmente en lenguas nativas filipinas. Los catálogos a menudo no contienen información correcta en este sentido. Por poner un ejemplo, en Worldcat aparecen dos obras con el mismo título, Agmoak Didiwiten que son traducciones del Noli me tangere. Según los catálogos, esta obra está en austronesio (primera entrada), tagalo (segunda entrada) y pangasinino (tercera y cuarta entradas). Dentro de la primera entrada, entre las bibliotecas que tienen la obra está la Cornell University. En la entrada a la obra aparece en la sección notas la siguiente nota "Impatalus ed Pangasinsn nen Lourdes Bengson Ungson", lo que en efecto nos pone en la pista de que el libro está en pangasinán. Estas cuestiones que por lo general podría resolver Google translate, son más difíciles en el caso de las lenguas filipinas, ya que el motor de búsqueda y traducción solo es capaz de traducir tagalo y cebuano de entre las 23 lenguas oficiales y regionales de Filipinas. En el caso del libro puesto como ejemplo, al introducir el título, Google Translate sugería que la lengua utilizada podía ser sudanés, lo que evidentemente es incorrecto.

\subsection{Herramientas utilizadas}

Filiteratura es una base de datos relacional construida en Heurist. Heurist es un gestor de bases de datos colaborativas de acceso abierto de uso académico desarrollada en la Facultad de Artes y Ciencias Sociales de la Universidad de Sydney desde 2005 bajo la dirección del Dr. Ian Johnson ${ }^{17}$. En su quinta versión, permite crear una web en el mismo servidor de la universidad a partir de búsquedas creadas o bien incrustarlas en una web como es el caso de Filiteratura, que está construida en Wordpress ${ }^{18}$.

Para sistematizar la búsqueda de obras y hacer la recopilación de los datos bibliográficos entre tres personas lo más rápida posible, recogimos primero los datos primero en Zotero $^{19}$, en dos bibliotecas grupales de lectura abierta, pero edición restringida a los miembros del grupo: una de obras editadas en Filipinas ${ }^{20}$ y otra de obras sobre Filipinas

\footnotetext{
${ }^{17}$ Véase https://heuristplus.sydney.edu.au/ [15/12/ 2019].

${ }^{18}$ Véase https://filiteratura.uantwerpen.be/database/ [18/12/2019].

${ }^{19}$ Véase https://www.zotero.org/ [15/12/2019].

${ }^{20}$ Véase https://www.zotero.org/groups/2243713/bofkpfilipinas/items [15/12/2019].
} 
de fuera de Filipinas ${ }^{21}$. En Zotero nos encargamos de unificar los títulos, lugares, nombres de autores y las editoriales. A menudo una editorial presenta diferentes nombres dependiendo del repositorio. Por ejemplo, la Imprenta de Juan Fajardo, aparece de múltiples maneras incluso dentro de la misma biblioteca. Muestro aquí un pequeño ejemplo con tres libros de tres bibliotecas en tres continentes diferentes: el catálogo de la Biblioteca Nacional de España (BNE), el de la Biblioteca de la University of the Philippines (UP) y la colección "The United States and its territories" de la Universidad de Michigan (U. Michigan), con obras escritas más o menos en torno a las mismas décadas (figura 1).

\begin{tabular}{|c|c|c|c|c|c|}
\hline \multicolumn{2}{|c|}{$\mathrm{BNE}$} & \multicolumn{2}{|c|}{ UP } & \multicolumn{2}{|c|}{ U. MICHIGAN } \\
\hline Título & $\begin{array}{c}\text { Datos de } \\
\text { publicación }\end{array}$ & Título & $\begin{array}{c}\text { Datos de } \\
\text { publicación }\end{array}$ & Título & $\begin{array}{c}\text { Datos de } \\
\text { publicación }\end{array}$ \\
\hline $\begin{array}{c}\text { Vía Crucis } \\
\text { [Texto impreso] }\end{array}$ & $\begin{array}{c}\text { [s.1.]: [s.n.], } \\
1904 \text { (Manila: } \\
\text { Imp. de } \\
\text { Fajardo y } \\
\text { Compañía) }\end{array}$ & $\begin{array}{l}\text { La madrasta: } \\
\text { novela histórico- } \\
\text { contemporánea/ } \\
\text { José Calonge } \\
\text { Sedano }\end{array}$ & $\begin{array}{c}\text { Manila: Imp. } \\
\text { y Lit. de Juan } \\
\text { Fajardo, } 1910 .\end{array}$ & $\begin{array}{l}\text { Bancarrota de } \\
\text { almas: novela } \\
\text { Filipina }\end{array}$ & $\begin{array}{c}\text { Manila: Librería } \\
\text { Manila } \\
\text { Filatélica, } 1910\end{array}$ \\
\hline $\begin{array}{c}\text { Bajo los } \\
\text { cocoteros [Texto } \\
\text { impreso]: (almas } \\
\text { y panoramas) } \\
\text { Recto, Claro M. } \\
\text { 1890-1960 }\end{array}$ & $\begin{array}{l}\text { Manila: [Juan } \\
\text { Fajardo]: } \\
\text { Librería } \\
\text { "Manila } \\
\text { Filatélico", } \\
1911\end{array}$ & $\begin{array}{l}\text { Quien es Retana: } \\
\text { su antaño y } \\
\text { hogaño. Reseña } \\
\text { bio-bibliográfica / } \\
\text { Manuel Artigas y } \\
\text { Cuerva. }\end{array}$ & $\begin{array}{c}\text { Manila: Impr. } \\
\text { y Litografia de } \\
\text { Juan Fajardo, } \\
1911 .\end{array}$ & $\begin{array}{l}\text { Quien es Retana: } \\
\text { su Antaño y } \\
\text { Hogaño reseña } \\
\text { bio-bibliográfica }\end{array}$ & $\begin{array}{l}\text { Manila: Imprenta y } \\
\text { Litografía de Juan } \\
\text { Fajardo, } 1911\end{array}$ \\
\hline $\begin{array}{c}\text { Monroísmo } \\
\text { Asiático [Texto } \\
\text { impreso]: } \\
\text { (artículos de } \\
\text { polémica) y } \\
\text { otros ensayos } \\
\text { Recto, Claro M. } \\
\text { 1890-1960 }\end{array}$ & $\begin{array}{l}\text { Manila: [s.n.], } \\
1929 \text { (Imp. de } \\
\text { Juan Fajardo) }\end{array}$ & $\begin{array}{c}\text { Monroismo } \\
\text { Asiático } \\
\text { (artículos de } \\
\text { polémica) y otros } \\
\text { ensayos. Con un } \\
\text { prólogo de Pedro } \\
\text { Aunario / Claro } \\
\text { Mayo Recto. }\end{array}$ & $\begin{array}{c}\text { Manila: } \\
\text { Imprenta de } \\
\text { Juan Fajardo, } \\
{[\mathrm{c} 1929]}\end{array}$ & $\begin{array}{c}\text { Almanaque } \\
\text { Manila galante } \\
\text { para el año } 1912\end{array}$ & $\begin{array}{l}\text { Manila: Imp. Lit. y } \\
\text { Encuadernación de } \\
\text { Juan Fajardo, } 1912\end{array}$ \\
\hline
\end{tabular}

Figura 1. Tabla en la que se observan los diferentes nombres que se le da a la Imprenta y Litografía de Juan Fajardo en los catálogos de tres bibliotecas diferentes.

He resaltado en negrita los diferentes nombres dados a la misma imprenta editorial. En ocasiones se complica todavía más: en el caso de la

${ }^{21}$ Véase https://www.zotero.org/groups/2258548/bofkpenespanolsobrefilipinas/items [15/12/2019]. 
Imprenta de los dominicos de la Universidad de Santo Tomás, de las más antiguas de Filipinas, el nombre va evolucionando, incluyendo el nombre de los diferentes editores y cambiando de idioma y filiación (de vez en cuando es de los dominicos, de vez en cuando de Santo Tomás y eventualmente en el siglo XX pasa a ser UST Press).

En Zotero nos aseguramos de que todas las obras de esa misma imprenta tengan el mismo nombre consensuado. Las variaciones de cada imprenta/editorial/litografía se apuntan en una hoja de cálculo compartida y se añaden a la sección nombres alternativos de la ficha de dicha imprenta en Heurist. Igualmente, se revisan todos los títulos y nombres de autores para asegurarnos de que no hay discrepancias por erratas o por uso de iniciales en vez del nombre completo. A partir de ahí, intentamos importar directamente las entradas en Heurist, pero hubo dificultades con la coincidencia de los campos y pérdidas de datos, por lo que fuimos subiendo los datos uno por uno.

Ya en Heurist se intenta ofrecer una imagen en el perfil de cada autor y cada edición (del autor y de la portada de la edición respectivamente). Esta imagen, para evitar problemas de derechos, no está en la propia base de datos, sino que es por lo general una previsualización de un enlace existente en otro lugar en Internet. Así, aunque se ha solicitado permiso a las bibliotecas para enlazar a sus repositorios, no existen en realidad problemas de autoría, puesto que Filiteratura no contiene ninguna obra y ninguna imagen: solo enlaza a ellas y proporciona información sobre las mismas. Además, cuando cierta información sobre obras o autores es debatible o existen varias versiones, se suele ofrecer en la sección comentarios de la ficha relevante las referencias de donde se ha extraído la información.

\section{RESULTADOS}

Una base de datos relacional se compone por un conjunto de tablas que a su vez tienen campos y registros. Como los datos tienen forma tabular, se pueden presentar relaciones entre ellos. Cada tabla representa un tipo de entidad (por ejemplo, libro, persona, edición o lugar). Estas contienen filas, que representan cada instancia de un tipo de entidad (por ejemplo, 
dentro de libro, una fila sería Noli me tangere, otra Bajo los cocoteros, otra Bancarrota de almas, etcétera). Las columnas, también llamadas atributos, representan valores de cada tipo de entidad. Por ejemplo, en nuestro caso, el tipo de entidad libro tiene los atributos autor, título y género.

Con este sistema optimizamos la recopilación y la organización de datos (se evita la repetición de datos en más de un campo), y además logramos gran capacidad para entrar en detalle por medio de preguntas complejas y tejer redes. Es decir, que, a diferencia de lo que sucede con un catálogo común, con Filiteratura podemos responder a preguntas como cuántas mujeres filipinas publicaron libros en cualquier parte del mundo en determinadas décadas, o bien qué géneros publicaba más una determinada imprenta, o qué géneros abordaban los autores y autoras que publicaban en un determinado periódico sin repetir datos, lo cual puede ser muy útil a la hora de describir la historia de la literatura de y sobre Filipinas.

Para lograr esto, dentro de Heurist se han creado unas búsquedas predeterminadas en las que se pueden seleccionar atributos de varios campos relacionados a la vez. Así pues, aunque la tabla libros no incluye los años de edición de un determinado libro ni el año de nacimiento del autor, estos datos se pueden encontrar en la tabla ediciones, relacionada con libros y en la tabla persona también relacionada con libros. La estructura de la base de datos con la que conseguimos esto es la siguiente (figura 2):

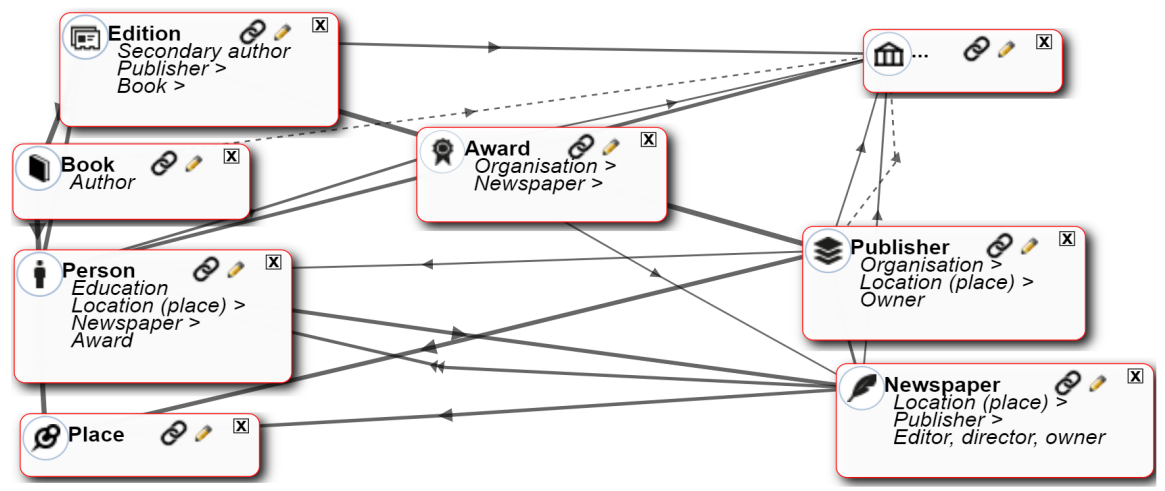

Figura 2. Estructura de la base de datos relacional en Heurist.

De este modo se pueden ver no solo las conexiones literarias evi- 
dentes entre autor y todos sus libros, sino también plantearnos el canon al observar la popularidad de la obra de un autor por medio de las reediciones de sus libros, cuestiones políticas como la relación entre editoriales, periódicos y organizaciones (sea eclesiásticas como la Universidad de Santo Tomás, sea políticas como Editora Nacional, por poner dos casos), la relación entre premios, organizaciones y periódicos, y a quién le han dado qué premios (y por tanto, posiblemente, las simpatías políticas o religiosas y su papel en la formación de los cánones).

A la hora de seleccionar una entidad aparece una ficha con todos los campos. Aquellos que se pueden explorar porque están relacionados con otra entidad (por ejemplo, los libros del autor o autora), aparecen en azul, como se ve en las figuras 3, 4 y 5 .

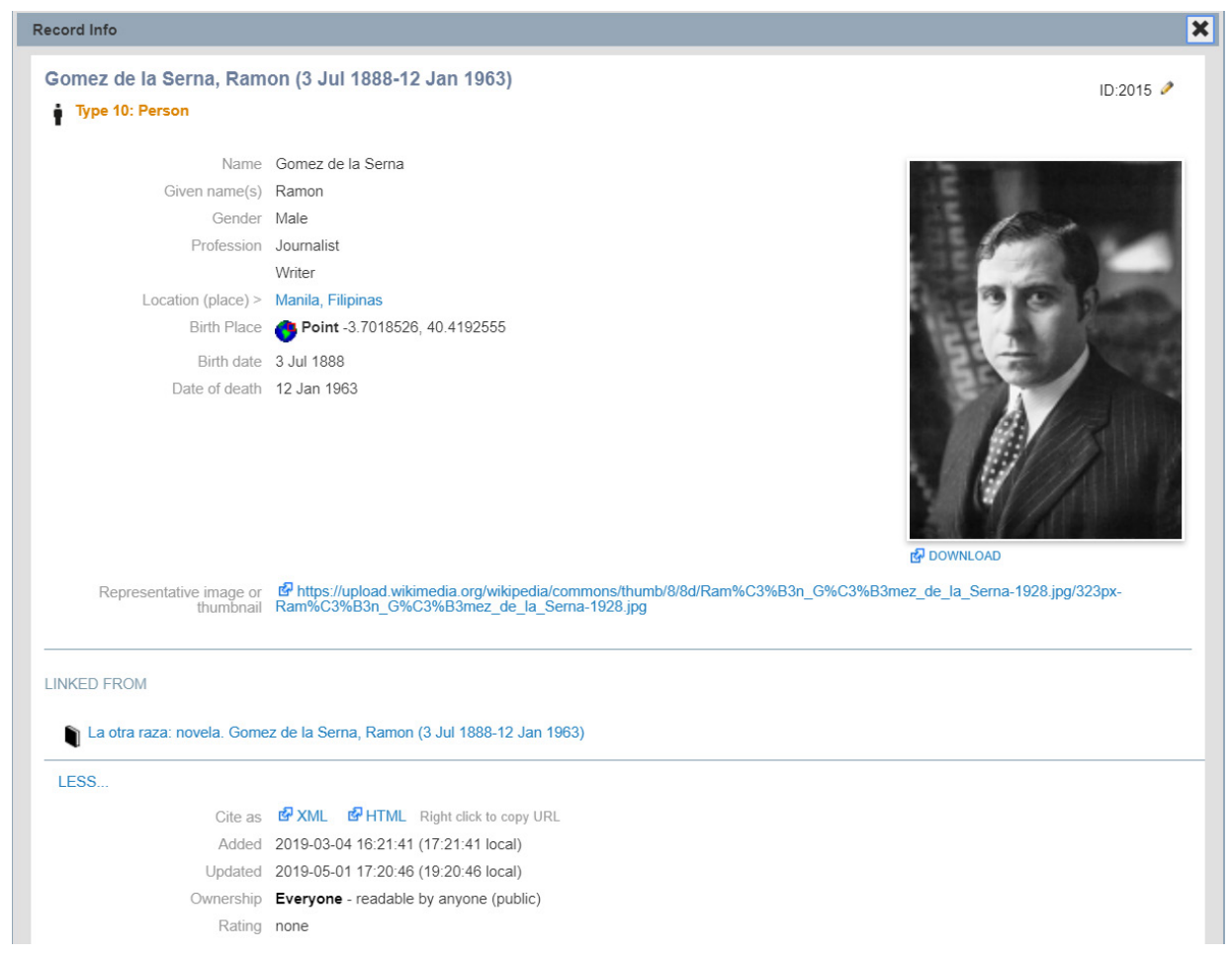

Figura 3. Ficha de autor de Ramón Gómez de la Serna en Filiteratura. 


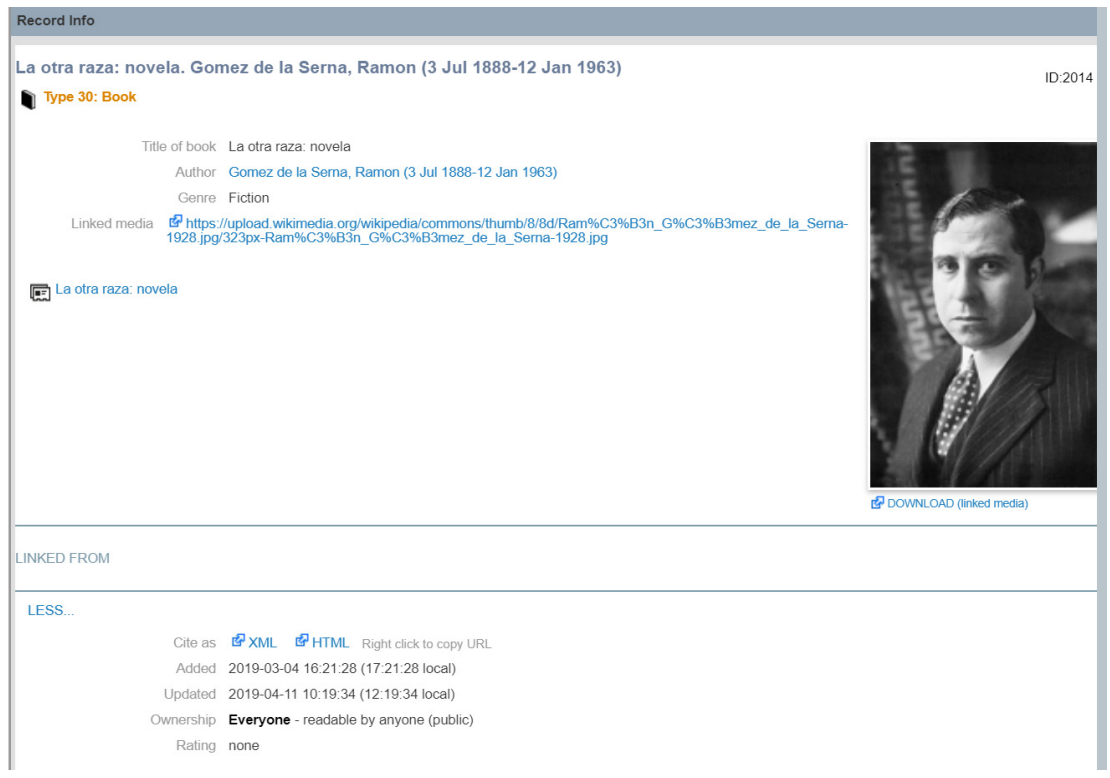

Figura 4. Ficha de la novela La otra raza de Ramón Gómez de la Serna en Filiteratura.

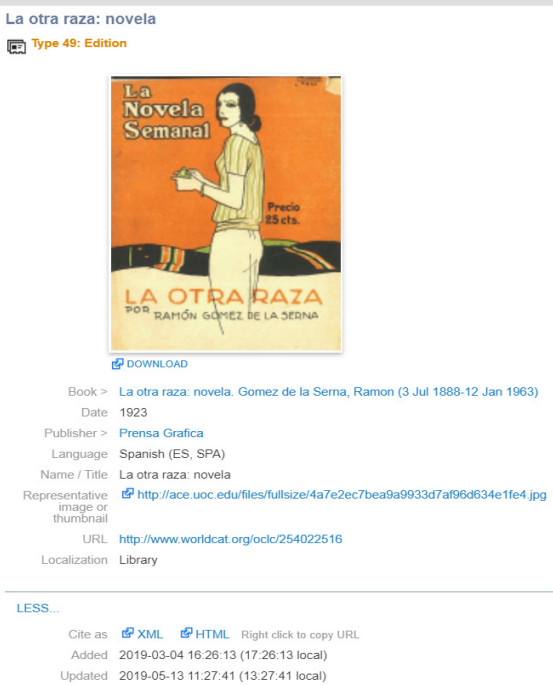

Figura 5. Ficha de la edición de la novela La otra raza de Ramón Gómez de la Serna en Filiteratura. 


\subsection{Entidades y atributos}

Dentro de las entidades y los atributos creados hay algunas especifidades que pueden no ser tan obvias como deberían y que paso a explicar.

En primer lugar, se ha distinguido edición y libro como entidades diferentes. El libro se considera la creación del autor, el manuscrito, que solo tiene género y autor como atributos característicos del mismo. Después, cada libro se reproducirá $\mathrm{x}$ veces o instancias que son las ediciones y que tienen dentro de la base de datos una entrada diferente. Esas ediciones podrán estar en diferentes idiomas, tener autores secundarios - en este caso se ha considerado autores secundarios a los escritores de prólogos, epílogos, proemios etcétera, lo que también ayuda a comprender las redes sociales de la literatura en torno a Filipinas - tener fechas y lugares de publicación y estar vinculados a instituciones o editoriales que los publican. Las búsquedas, se pueden hacer por libros - en tal caso, en la ficha de cada libro aparecerán todas las ediciones debajo- o por ediciones.

En segundo lugar, dentro de la entidad persona están incluidos editores/as, directores/as y redactores/as de periódicos, traductores/as (como autores/as secundarios) y escritores/as. Esto ocurre porque a menudo una persona ha ejercido múltiples papeles, y para dibujar la red de relaciones entre los diferentes elementos de los campos literario, cultural y político, conviene poder relacionar todo con esta misma persona.

Para simplificar, toda aquella persona que ha escrito un libro es considerada "writer" (escritor/a), toda aquella que ha escrito alguna vez en un periódico es considerada "journalist" (periodista). Si se quiere encontrar una lista de autores y autoras, habrá por tanto que elegir primero el oficio writer. Además, pueden aparecer otros oficios que para facilitar los estudios cuantitativos se han simplificado. Así pues, cualquier persona que haya desempeñado un puesto político será politician, cualquiera que haya estado en el ejército en cualquier puesto tendrá entre sus oficios army y el que haya sido abogado defensor, fiscal o juez, tendrá law.

Dentro de la entidad persona también están los atributos location place y birth place. En ambos casos se trata del mismo lugar, el lugar de nacimiento del autor. En el primer caso se dan el nombre de la provincia (si se conoce) y del país en inglés. En el segundo caso se dan unas coordenadas para posibilitar la visualización en el mapa. Los resultados en datos 
y en el mapa pueden variar. Esto es porque no de todos los escritores tenemos datos de nacimiento. En estos lugares, y una vez más con la intención de facilitar los estudios cuantitativos, todos los municipios que componen Metro Manila se han incluido como Metro Manila. Asimismo, los barangays (barrios filipinos a menudo con entidad administrativa propia) se han identificado con la ciudad principal a la que pertenecen.

\subsection{Búsquedas}

Dado que la información sobre periódicos, imprentas y premios es aún incipiente, Filiteratura ha arrancado con tres tipos de búsqueda: personas, libros y ediciones. Estas tres búsquedas están incrustadas en la web creada en WordPress Filiteratura. En ellas se pueden encontrar las siguientes entidades y atributos:

\begin{tabular}{|c|c|c|c|c|c|}
\hline \multicolumn{2}{|r|}{ Personas } & \multicolumn{2}{|r|}{ Libros } & \multicolumn{2}{|r|}{ Ediciones } \\
\hline Atributo & $\begin{array}{c}\text { Forma de } \\
\text { inserción }\end{array}$ & Atributo & $\begin{array}{c}\text { Forma de } \\
\text { inserción }\end{array}$ & Atributo & $\begin{array}{c}\text { Forma de } \\
\text { inserción }\end{array}$ \\
\hline Apellido & $\begin{array}{r}\text { Introducción } \\
\text { manual de } \\
\text { texto }\end{array}$ & Título & $\begin{array}{r}\text { Introducción } \\
\text { manual de } \\
\text { texto }\end{array}$ & Título & $\begin{array}{r}\text { Introducción } \\
\text { manual de } \\
\text { texto }\end{array}$ \\
\hline $\begin{array}{r}\text { Fecha de } \\
\text { nacimiento }\end{array}$ & $\begin{array}{r}\text { Selección de } \\
\text { rango }\end{array}$ & Género & $\begin{array}{r}\text { Selección } \\
\text { entre opcio- } \\
\text { nes de lista } \\
\text { desplegable }\end{array}$ & $\begin{array}{r}\text { Fecha de } \\
\text { publicación }\end{array}$ & $\begin{array}{r}\text { Selección de } \\
\text { rango }\end{array}$ \\
\hline $\begin{array}{l}\text { Fecha de fa- } \\
\text { llecimiento }\end{array}$ & $\begin{array}{r}\text { Selección de } \\
\text { rango }\end{array}$ & $\begin{array}{r}\text { Apellido del } \\
\text { autor/a }\end{array}$ & $\begin{array}{r}\text { Introducción } \\
\text { manual de } \\
\text { texto }\end{array}$ & $\begin{array}{r}\text { Apellido del } \\
\text { autor/a }\end{array}$ & $\begin{array}{r}\text { Introducción } \\
\text { manual de } \\
\text { texto }\end{array}$ \\
\hline Género & $\begin{array}{r}\text { Selección en- } \\
\text { tre opciones: } \\
\text { female, male, } \\
\text { unknown }\end{array}$ & $\begin{array}{r}\text { Género del } \\
\text { autor/a }\end{array}$ & $\begin{array}{r}\text { Selección en- } \\
\text { tre opciones: } \\
\text { female, male, } \\
\text { unknown }\end{array}$ & $\begin{array}{r}\text { País de na- } \\
\text { cimiento del } \\
\text { autor/a }\end{array}$ & $\begin{array}{r}\text { Selección entre } \\
\text { opciones. }\end{array}$ \\
\hline Profesión & $\begin{array}{r}\text { Selección } \\
\text { entre opcio- } \\
\text { nes de lista } \\
\text { desplegable }\end{array}$ & $\begin{array}{r}\text { Localidad de } \\
\text { nacimiento } \\
\text { del autor/a }\end{array}$ & $\begin{array}{r}\text { Introducción } \\
\text { manual de } \\
\text { texto }\end{array}$ & $\begin{array}{r}\text { Género del } \\
\text { autor/a }\end{array}$ & $\begin{array}{r}\text { Selección en- } \\
\text { tre opciones: } \\
\text { female, male, } \\
\text { unknown }\end{array}$ \\
\hline
\end{tabular}




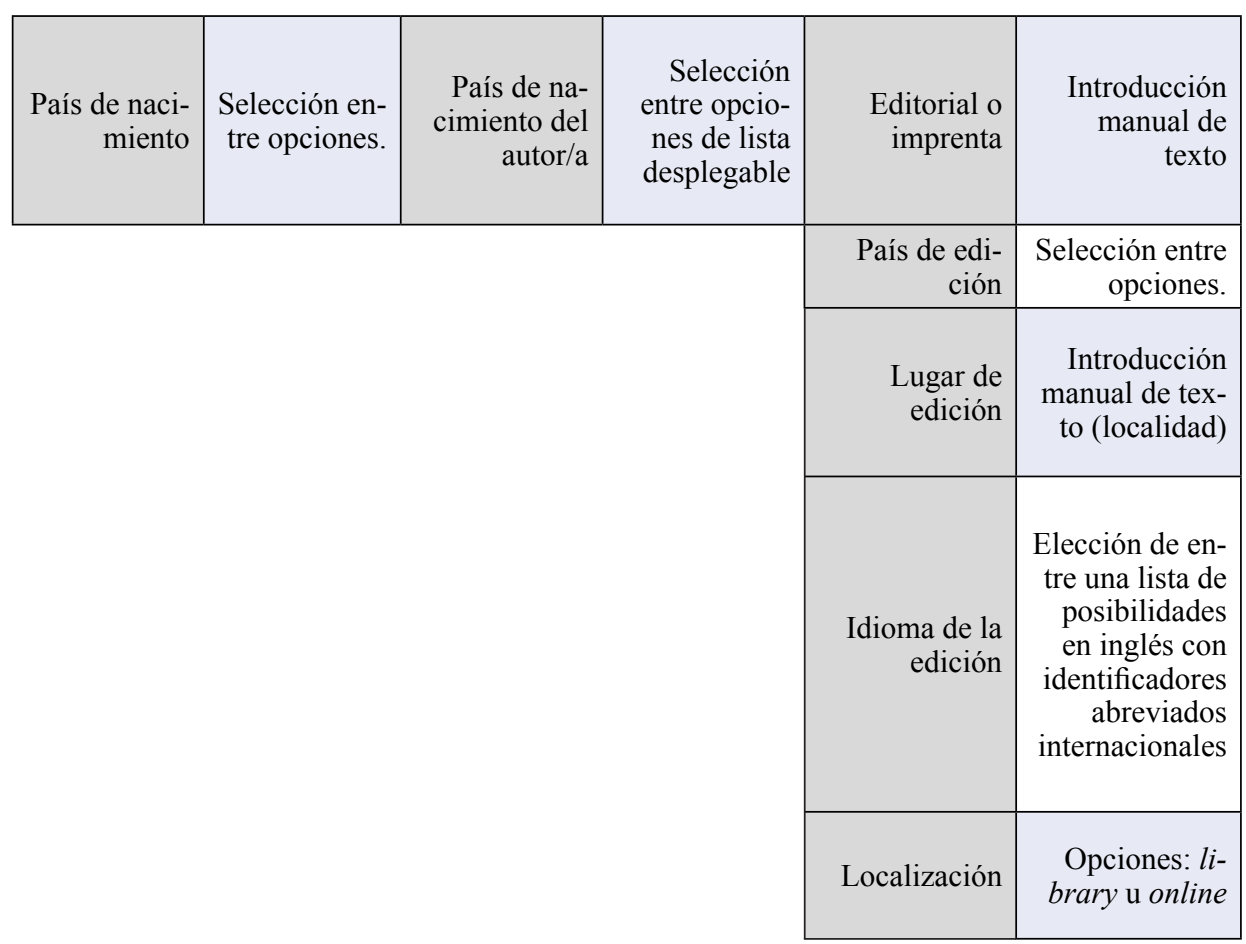

Figura 6. Lista de atributos por entidad de la base de datos relacional Filiteratura.

De este modo es como, sin conocimientos de SQL (Structured Query Language), se pueden realizar preguntas complejas como cuántas mujeres nacidas en España entre 1830 y 1915 escribieron libros, poesías o relatos (pero todo publicado en forma de libro) sobre Filipinas. La respuesta, por cierto, es seis de momento presentes en Filiteratura: Enriqueta Lozano de Vilchez, Susana March, Josefa Menéndez, Emilia Pardo Bazán, Gloria de la Prada Navarro y Elena Sánchez de Arrojo. Los resultados de esta y de cualquier otra consulta se pueden ver en forma de lista, de miniaturas de imágenes, de líneas temporales o de mapa (Figura 7), dependiendo de las características de los datos que aparezcan. 


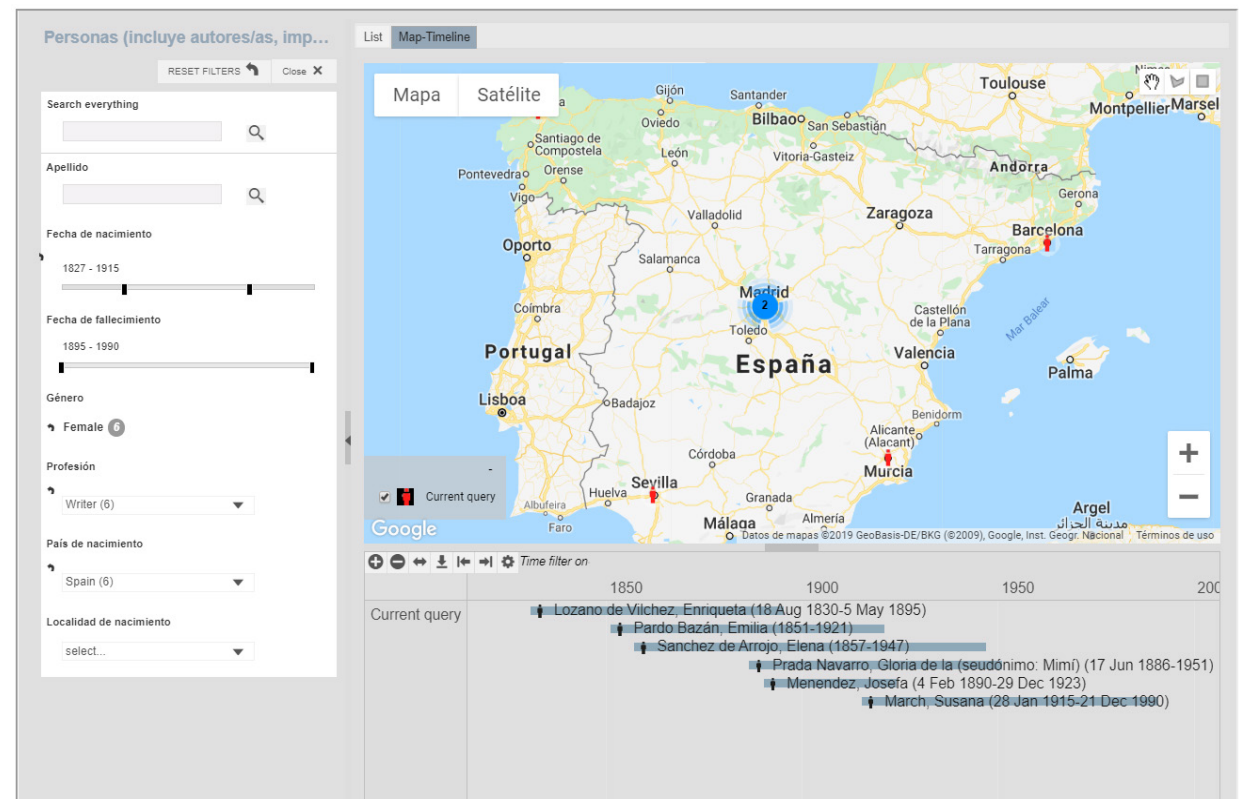

Figura 7. Visualización en forma de mapa con el lugar de nacimiento y de línea temporal (debajo) de las mujeres escritoras españolas nacidas entre 1827 y 1915 y que escriben sobre Filipinas, con lo que están contenidas en Filiteratura.

La cuestión de las búsquedas predeterminadas tiene, eso sí, algunas limitaciones. Por ejemplo, desde la búsqueda de autores no se puede saber los que publicaron o libros entre ciertas fechas. Por otro lado, hay una falta de certeza sobre la fecha de redacción de un manuscrito respecto a la de su publicación como volumen ${ }^{22}$ que impide sin una investigación más detallada incluir la franja temporal en la que un autor estuvo activo.

Más allá de las limitaciones, las búsquedas bibliográficas realizadas para construir la base de datos ya han dado algunos resultados dignos de mención. Uno de ellos es la expansión temporal de la producción literaria filipina. Por lo general se ha considerado que la última novela filipina en español fue La vida secreta de Daniel Espeña, escrita por Antonio Abad y publicada en 1960. Gracias a Filiteratura y a las búsquedas con diferentes parámetros en las bibliotecas, desafiando erratas, se ha hallado una novela

\footnotetext{
${ }^{22} \mathrm{El}$ manuscrito puede haber sido publicado antes en prensa, por ejemplo, como ocurre con todas las novelas de José Felipe del Pan, que aparecen como segunda edición porque la primera apareció por fascículos en La Oceanía española.
} 
más tardía del mismo autor, mecanografiada, pero sin publicar, de 1963. Además, se ha descubierto gracias a un artículo ensayístico de Alejo Valdés Pica que aparecía en uno de los volúmenes incluidos, sendos libros de Ramón Gómez de la Serna y de Alfonso Hernández Catá aparecidos en la colección La novela semanal de los años 20, que tratan sobre Filipinas. Es curioso en el caso del primero, la representación orientalizada y de extrañeza que hace de los filipinos, cuando como afirma en su propia autobiografía, estaba habituado a su presencia en la casa de su padre, que había sido largo tiempo funcionario de Ultramar en Manila y que aparece como autor secundario de la Vida y escritos del Dr. José Rizal, compilados por W. Retana en 1907.

Yendo a la parte más cuantitativa de lectura distante, Filiteratura ha compilado 88 autores y autoras filipinos que escriben en español y 182 españoles que tratan sobre Filipinas. De los españoles 86 nacieron entre 1830 y 1915.10 de los filipinos son mujeres y 15 de los españoles también lo son. Muchos de los españoles como Wenceslao Retana y José María Romero Salas y de los filipinos como José Rizal y Adelina Gurrea entre muchos otros, escriben tanto en periódicos filipinos como españoles, pero en esto todavía habrá que profundizar.

\section{PERSPECTIVAS}

A pesar de que los resultados son esperanzadores, hay aún objetivos que posibles que han quedado sin cumplirse con la actual base de datos. Entre ellos dos principales:

- Completar la reconstrucción de los campos literario y cultural en torno a Filipinas con todos los actores, hayan publicado en libro o en prensa para asentar las bases de una historia de la literatura filipina en español que inevitablemente deberá incluir una historia de la prensa en Filipinas.

- Facilitar la vinculación de Filiteratura a otras bases de datos similares para visibilizar el papel que tuvo Filipinas en la literatura hispanohablante de los siglos XIX y XX y sacar a la luz posibles lazos entre otras áreas hispanohablantes y Filipinas por medio de escritores, periodistas o impresores. 
Por esto, se planea una segunda fase para Filiteratura, en la que deberá desarrollarse de la siguiente manera.

En primer lugar se aumentarán los registros de periódicos, imprentas y premios incluyendo los que hay en las obras bibliográficas de Artigas Cuerva y de Wenceslao Retana y en el catálogo de la biblioteca filipina de la librería de Pedro Vindel, además de los que aparecen en la guía de periodistas españoles del siglo XIX elaborada por Manuel Ossorio y Bernard, en la que además de los nombres de múltiples periodistas y escritores que anduvieron entre España y Filipinas, encontramos información sobre los periódicos españoles en los que estos colaboraron, información que también habría que incluir en Filiteratura (Artigas y Cuerva, 1906; Retana 1900, 1908, 1895; Vindel, 1904; Manuel Ossorio y Bernard, 1903).

En segundo lugar, se va a realizar un etiquetado de los libros por tema y, si fuera posible, de los periódicos por línea editorial usando un vocabulario controlado. En el caso de los libros, más allá de los géneros, interesa saber qué temas se relacionan con las obras sobre Filipinas. Este etiquetado temático se ha intentado en varias bibliotecas con éxito variable: a menudo existen inconsistencias y no todos los elementos de un grupo están etiquetados de forma acertada como integrantes de dicho grupo. Además, en muchos casos, el etiquetado se suele limitar al género. Algunos temas como II Guerra Mundial, o Revolución Filipina, no aparecen como subconjunto de las obras filipinas en español y deberían. Siendo uno de los objetivos de la base de datos asentar las bases para una historia de la literatura filipina en español, interesa saber los temas más tratados y más leídos en cada época y su relación con otros parámetros como la profesión de los escritores. Se podría así responder preguntas como si escriben los políticos más libros de viajes o si las memorias de la II Guerra Mundial fueron mayoritariamente escritas por religiosos, como punto de partida en la elaboración de análisis e hipótesis.

En tercer lugar, se va a reforzar un aspecto ya existente como es la colaboración de lectores y usuarios. De momento hay una página de contacto en WordPress a la que los usuarios pueden enviar sus sugerencias de nuevas entidades (obras, ediciones, autores, imprentas, periódicos, premios y organizaciones), seudónimos pertenecientes a autores presentes en la base de datos, $\mathrm{u}$ otra información relevante para que pase a integrar la colección. Lo que queremos hacer es incluir a las personas interesadas 
como colaboradores directamente de los grupos de Zotero y de Heurist para que puedan subir las entradas que vean necesarias sin pasar antes por la gestión previa. Una vez hecho esto, las entradas son revisadas y aprobadas para su visualización pública.

En cuarto lugar, se pretende ampliar la base de datos con obras aparecidas en periódicos y revistas, tanto cuentos, como poemas, libros de viaje o novelas aparecidas por entregas. Para esto y para completar el mapa de los autores activos, se seguirán dos procedimientos: por un lado, se conectará la base de datos Filiteratura al repositorio Philperiodicals. Este repositorio cuenta implementa el protocolo IIIF, con lo que partes de la imagen del periódico se pueden vincular directamente a un autor o como obra. Estar en Heurist supone ciertas limitaciones en la previsualización de estos enlaces y la búsqueda por texto, así que podría ser necesario salir del gestor de bases de datos. Por otro lado, se vinculará mediante enlaces e incrustación de imágenes cuando sea necesario y lo permitan las hemerotecas digitales, a otros periódicos que no estén en Philperiodicals. Las hemerotecas digitales propuestas son la Hemeroteca Municipal de Madrid que tiene periódicos digitalizados en el repositorio Memoria de Madrid, la Hemeroteca Digital Hispánica de la Biblioteca Nacional, la Biblioteca Virtual de Prensa Histórica de España, la Biblioteca digital de la Universidad de Santo Tomás de Manila y una vez más, Archive.org. El caso de la Biblioteca digital de la Universidad de Santo Tomás puede ser algo más complicado al ser el único que no tiene capa de texto en las imágenes de sus periódicos.

Finalmente, en quinto lugar, incidiendo en el objetivo de facilitar el trabajo de los investigadores, se hará un mapa de bibliotecas que contienen obras de Filiteratura. En este trabajo será también crucial la ayuda de los colaboradores.

\section{CONCLUSIONES}

Filiteratura ha conseguido el hito de reunir en una misma base de datos la literatura en español de y sobre Filipinas. Por medio de esta herramienta se han cuestionado los límites actuales de la literatura filipina en español, se ha puesto de relieve la amplia producción sobre Filipinas que hubo durante la Edad de Plata, cuestionando lo que se ha venido 
diciendo al respecto (Valmaseda, 2014), se tiene una noción de lo que se leía y editaba en Filipinas en español y se han localizado obras hasta ahora difíciles de encontrar o que no se sabía si seguían existiendo. Aun así, el trabajo continúa y se espera que la base de datos siga creciendo y centralizando recursos sobre Filipinas uniéndose con otros proyectos sobre campos literarios en el mundo hispanohablante y sobre prensa y literatura.

\section{REFERENCIAS BIBLIOGRÁFICAS}

ARTIGAS Y CUERVA, M. (1906). Los periódicos filipinos: la más completa bibliografía publicada hasta la fecha acerca de los papeles públicos filipinos. Manila: Biblioteca Nacional Filipina. Disponible en línea: http://archive.org/details/arb8044.0001.001. umich.edu [18/12/2019].

BARDAVÍO-ESTEVAN, S. (2018). “¡España es también aquí!’: Nación e imaginario colonial en los cuentos de Emilia Pardo Bazán”. Castilla: Estudios de Literatura 9, 176-203. Disponible en línea: https://doi.org/10.24197/cel.9.2018.176-203 [05/12/2019].

DE LA PEÑA, W. (2011). "Revisiting the Golden Age of Fil-Hispanic Literature (1898-1941)". En Pilipinas типа! Филиппинь прежде всего!: К 80-летию Геннадия Евгеньевича Рачкова. I Pilipinas muna! Filipinas principalmente: ensayos en honor del 80 aniversario de Gennady Paton Rachkova, AA.VV. (eds.), 119-27. Sankt-Peteburg: Kuntskamera.

DONOSO, I. y GALLO, A. (2011). Literatura hispanofilipina actual. Madrid: Verbum.

GARCÍA CASTELLÓN, M. (2001). Estampas y cuentos de las Filipinas Hispánicas. Madrid: Clan.

HERNÁNDEZ, V. S. (2001). "Trends in Philippine Library History", Libraries \& Culture 36.2, 329-344.

KAPCHAN, D. A. \& STRONG, P. T. (1999). "Theorizing the Hybrid". The Journal of American Folklore 112.445, 239-253.

LOZANO DE VILCHEZ, E. (1893). Emma Delaunay: novela orijinal de D.a Enriqueta Lozano de Vilchez. Manila: Imprenta de la Revista 
"Mercantil".

MARIÑAS OTERO, L. (1974). La literatura filipina en castellano. Madrid: Editora Nacional.

MARTÍNEZ SAN MARTÍN, A. y GARRIDO GALLARDO, M. Á. (1983). La narrativa de Felipe Trigo. Madrid: CSIC.

MOJARRO, J. (2019). "Traspacific Connections of Philippine Literature in Spanish. An Introduction”. Unitas 92.1, 1-5. Disponible en línea: http://unitasust.net/wp-content/uploads/2019/11/UNITAS-92-1Guest-Editor-Introduction.pdf [07/02/2020].

ORTIZ ARMENGOL, P. (1999). Letras en Filipinas. Madrid: Dirección General de Relaciones Culturales y Científicas / Ministerio de Asuntos Exteriores.

ORTUÑO CASANOVA, R. (2014). Literatura filipina en español. Portal de la Biblioteca Virtual Miguel de Cervantes. Disponible en línea: http://www.cervantesvirtual.com/portales/literatura_filipina_en_ espanol/ [09/12/2019].

(2017). "Philippine Literature in Spanish: Canon Away from Canon". Iberoromania: Revista dedicada a las lenguas y literaturas iberorrománicas de Europa y América 85, 58-77.

ORTUÑO CASANOVA, R. Y SARMIENTO, A. (2020). "Humanidades Digitales en Filipinas: proyectos, dificultades y oportunidades de la colaboración Norte-Sur". Digital Scholarship in the Humanities, fqz086. Disponible en línea: https://doi.org/10.1093/llc/fqz086 [06/11/2020].

OSSORIO Y BERNARD, M. (1903). Ensayo de un catálogo de periodistas españoles del siglo XIX. Madrid: Imprenta y litografía de J. Palacios. Disponible en línea: http://archive.org/details/ ensayodeuncatlo00berngoog [18/12/2019].

PRATT, M. L. (2017). Imperial eyes: travel writing and transculturation. London / New York: Routledge / Taylor \& Francis.

RETANA, W. E. (1895.) Archivo del bibliófilo filipino; recopilación de documentos históricos, cientificos, literarios y políticos, y estudios bibliográficos. Madrid: Viuda de M. Minuesa de los Ríos. Disponible en línea: https://catalog.hathitrust.org/Record/006054380 [18/12/2019].

(1900). El periodismo filipino Noticias para su historia (1811-1894) Apuntes bibliográficos, indicaciones biográficas, notas críticas, 
semblanzas, anécdotas. Madrid: Viuda de M. Minuesa de los Ríos. (1906). Aparato bibliográfico de la historia general de Filipinas deducido de la colección que posee en Barcelona la Compañía General de Tabacos de dichas islas. Madrid: Viuda de M. Minuesa de los Ríos.

(1908). Tablas cronológica y alfabética de imprentas é impresores de Filipinas (1593-1898). Madrid: Lib. General de Victoriano Suárez. (1909). De la evolucion de la literatura Castellana en Filipinas: los poetas, apuntes criticos. Madrid: Lib. General de Victoriano Suárez.

RODAO, F. (1996). "La lengua española en Filipinas durante la primera mitad del siglo XX". Estudios de Asia y Africa 31.1(99), 157-175.

SUSMITA, C. (2013). Collaboration in International and Comparative Librarianship. Hershey, PA: IGI Global.

TIONGSON, N. G. (ed.) (1994). CCP encyclopedia of Philippine art. Literature. Manila: Cultural Center of the Philippines.

TORRADO, A. (1948). Mi tía de Filipinas. Madrid: Ed. Rollán.

URRUTIA CÁRDENAS, H. (2000). "La Edad de Plata de la literatura española (1868-1936)”. Cauce: Revista Internacional de Filología, Comunicación y sus Didácticas 22-23, 581-595. Disponible en línea: http://hdl.handle.net/11441/30459 [05/12/2019].

VALMASEDA, C. (2014). "La imagen de Filipinas en la literatura española del siglo XIX". Perro Berde. Revista Cultural Hispano-Filipina 5, 25-29. Disponible en línea: http://www.cervantesvirtual.com/obra/ la-imagen-de-filipinas-en-la-literatura-espanola-del-siglo-xix/ [05/12/2019].

VINDEL, P. (1904). Catálogo Sistematico é Ilustrado de la Biblioteca Filipina Reunida Y Puesta en Venta Por P. Vindel. Madrid: Librería de Pedro Vindel. Disponible en línea: http://archive.org/details/ catlogosistemat03vindgoog [18/12/2019].

Recibido el 13 de marzo de 2020.

Aceptado el 29 de abril de 2020. 